\title{
Metric Analysis of the Information visibility and diffusion about the European Higher Education Area on Spanish University Websites
}

María Pinto, University of Granada, Department of Information Science, Po de Cartuja, s/n, 18071, Granada, Spain, e-mail: mpinto@ugr.es

Dora Sales, Universitat Jaume I, Department of Translation and Communication, Avda. Sos Baynat, s/n, 12071, Castellón, Spain, e-mail: dsales@trad.uji.es

Anne-Vinciane Doucet, University of Granada, Scholarship Holder, Department of Information Science, e-mail: vinciane.doucet@gmail.com

Andrés Fernández-Ramos, University of Granada, Scholarship Holder, Department of Information Science, e-mail: afernandezster@gmail.com

David Guerrero, University of Granada, Vicerrectorado de Planificación, Calidad y Evaluación docente, e-mail: dguerrero@ugr.es

\begin{abstract}
The purpose of the study proposed in this paper is to evaluate the Spanish public university websites dedicated to the European Higher Education Area (EHEA). To do so, the quality of these resources has been analysed in the light of data provided by a series of indicators grouped in seven criteria, most of which were used to determine what information is made available and in what way. The criteria used in our analysis are: visibility, authority, updatedness, accesibility, correctness and completeness, quality assessment and navigability. All in all, the results allow us to carry out an overall diagnosis of the situation and also provide us with information about the situation at each university, thus revealing their main strengths, namely authority and navegability, and also their chief shortcomings: updatedness, accessibility and quality assessment. In this way it is possible to detect the best practices in each of the aspects evaluated so that they can serve as an example and guide for universities with greater deficiencies and thus help them to improve their EHEA websites.
\end{abstract}

\section{Introduction}

Without a doubt information has always been a highly important component of social development and productive activity, but never before has it aroused so many expectations nor has it been so necessary to learn to handle it with rigour, and from critical and high quality perspectives. The growth of the Knowledge Society depends on the production of new knowledge, its transmission through education and information, its publication and dissemination through information and communication technologies, and its use by means of new industrial procedures or services. In today's Knowledge Society, all of us will have to learn to move with ease in the midst of the flood of information, and also to develop the cognitive abilities needed to distinguish useful, pertinent information from the rest. 
Nowadays, reinforcing the informative dimension of any organisation has become a real necessity and this is especially true of the institutions of higher education in Europe. These centres of learning now have to face an important challenge, namely, that of harmonising the culture of innovation with a long-term strategic vision of the organisation, its mission and goals, in order to foster learning outcomes within the scope of lifelong learning.

As we know, European universities are currently immersed in a reflexive, dynamic period in which they are experiencing a reassessment of the contents, forms and media used in teaching and learning. The creation of the EHEA represents an important challenge for all the countries involved.

The dissemination of information about the EHEA is therefore of interest to all of us in order to obtain a precise idea of its principles, together with its foundations, aims and goals, which we will outline in the next section of this work. At the same time, bearing in mind that "the Web is increasingly an important channel for information dissemination and retrieval" (Wang et al. 2000), a study of the extent to which the precepts and philosophy of the EHEA are distributed through university websites is undoubtedly relevant today.

Although reliable quality information on the subject (even if there is room for improvement) is available from the Ministry of Education and other institutions involved in the EHEA processs, the universities can play an important role in disseminating this information and drawing the attention of the members of their academic communities to the subject, providing them with quality access, and adapting this information to the specific needs of those communities from their own portal, thus removing any need to send them to any other resource.

With this goal in mind, this research centres its attention on evaluating the diffusion of information about the EHEA on websites published by Spanish universities, from both a quantitative and qualitative perspective recalling that the function of this portal is to facilitate access to all important information on the subject, and not merely to facilitate student exchanges. To do so, we developed a series of evaluation criteria and indicators that allow us to know what information about the EHEA is disseminated by our public universities, as well as its quality. The quantitative data obtained enabled us to carry out a qualitative evaluation of the situation of 
the universities included in the sample to detect their strong and weak points. Analysing all the results from this evaluation provided us with an overall view of the situation in Spanish universities that allowed us to highlight the points in need of improvement and to suggest the best practices we found for each case.

\section{The European Higher Education Area: a need and a challenge}

The great challenge of the university system is to make the European Higher Education Area a reality by 2010 , as is scheduled, starting from suitable initial undergraduate training as part of a more ambitious, lifelong training process, and assuming the changes for what they really are and for what they mean, i.e. as an 'opportunity' for improvement and not as a 'threat' to what already exists. As a result, the European university is currently going through a substantial transformation as regards the contents, forms and the media used in teaching and learning.

The implementation of the EHEA has been put forward in the successive declarations of the European Conference of Ministers of Higher Education, which outline the higher education institutions' main priorities and positions (Sorbonne, 1998; Bologna, 1999; Salamanca, 2001; Prague, 2001; Berlin, 2003; Graz, 2003; Bergen, 2005, and, forthcoming, London, 2007; for

further data, see http://www.eua.be/eua/index.jsp). These Declarations as a whole simultaneously offer a diagnosis and a model which is able to orient the evolution of European Higher Education in the new context.

Regarding the implementation of the Bologna reforms in Europe's universities, there is an obvious increase in investment in higher education as a means of responding to the demands of Europe's developing knowledge societies. After all, Europe's strength derives from the conception of higher education as a public responsibility responding to societal needs, and this requires the commitment to a long-term and sustainable public funding base in the context of the new European Higher Education Area (Reichert \& Tauch, 2005).

With regard to solutions, the new system aims at the reorganisation of the European universities so that, while respecting their cultural and legislative differences, they become transparent and competitive centres on a world-wide scale, with a clear labour-market orientation and a suitably 
articulated initial education within a more ambitious scope of lifelong learning (European Commission, 2001a). The Declarations reflect a search for a common European answer to common European problems. The process originates from the recognition that in spite of their valuable differences, European higher education systems are facing common internal and external challenges related to the growth and diversification of higher education, the employability of graduates, the shortage of skills in key areas, the expansion of private and transnational universities, and so forth.

The intensive use of the new technologies is also a relevant issue in this panorama, as has been emphasised by the European Commission (2001b). On this road towards convergence at European level, Spanish universities now have to face major changes arising from the restructuring of qualifications and curricula, the ever-greater proliferation of information and communications technology platforms in the educational sphere, and the implementation of the ECTS, bringing in its wake changes in both teaching and learning methods that will also affect information provision centres, libraries and resource centres for learning and research. The EHEA thus brings about a paradigm shift for learning at university level, with new scenarios and new services, centred on a meaningful and cooperative student learning process, with the teacher in a tutoring role encouraging the use of informational and technological resources.

Finally, the curriculum has to be flexible, so that each student can design his or her own curriculum, based on a harmonised system of qualifications and credits that allows for comparisons and offers a wide range of courses and contents, as well as joint and double qualifications. Such a system needs to be based on active methodologies, seeking the right balance within the teaching/learning binary and facilitating the best possible future for graduates (Reichert \& Tauch, 2005).

Only by organising an EHEA in accordance with principles of quality, mobility, diversity and competitiveness, and never losing sight of the fact that higher education is located at the crossroads of research, education and innovation, will we manage to progress towards the achievement of, among other things, two strategic objectives for Europe (González \& Wagenaar, 
2003), that is, an increase in employment in the EU and a European higher education system that is a pole of attraction for students and lecturers from around the globe.

\section{Evaluation of website quality. Review of the literature}

The ease with which electronic contents can be created with the web has favoured a huge boom in the amount of information available. Internet information is characterised by the instability of its contents, decentralisation of locations, multiplicity of forms, diversity of user groups, and dynamics of the environment (Zhang \& Dimitroff, 2005). But the quality of this vast amount of information now available on the Internet is not always as high as it perhaps should be, due to the fact that there are no guidelines (or at least they are not always followed) to ensure the quality of a web resource. It is therefore vital to know the desirable characteristics that this type of resources should offer so that their value and usefulness can be determined. Thus, as well as having criteria for evaluating a web resource in itself, we will have a tool for comparing different resources and observing, in organised fashion, how they are both different and similar (por ejemplo Overbeeke \& Snizek, 2005)

In order to conduct a study of the kind we propose here, it is essential to examine the distinct methodologies and analysis procedures that have been proposed in the scientific literature so that we can decide on how to go about the analysis of websites that we have set as the objective of our study.

From this review of the literature, it appears that two fundamental approaches are used to analyse websites. The first concerns cybermetric measures (size, impact, characteristics of their documents) and the second has to do with their quality. These two methods are complementary rather than mutually exclusive, the difference lying in the purpose of the study. In the first case, this would be basically descriptive while in the second the aim would be to detect their weak and strong points according to a series of criteria. In this work, we focus our attention on the second approach, that is to say, on evaluating their quality.

As stated by Gorksi (1999), "most of the criteria used to assess and evaluate traditional educational media such as textbooks and films can be directly applied to websites as well. These 
include: accuracy of the information, critical analysis of possible bias, credibility of the author and/or publishing source, appropriateness and accessibility (in terms of language) to the specified audience, timeliness, relevance to a particular subject area, validity of content, and effectiveness of aesthetic aspects", but "unlike the content of books or films, the information on websites is not static. Used responsibly, this can be a strength of websites. Information can be updated any time, new information can be added, and old information can be removed."

In a study of the literature published up to that time, Smith (1997) drew up a set of criteria for evaluating the quality of web-based resources and divided them into 7 categories: scope, content, graphic $\&$ multimedia design, purpose $\&$ audience, reviews, and workability and cost.

Both Alexander and Tate (1997) and Beck (1997) or Kapoun (1998) propose five fundamental criteria (accuracy, authority, objectivity, currency and coverage), together with the associated indicators that can be used to measure them.

Miller (1996) deals with the different dimensions from which the relevance and accuracy of web resources can be perceived: its currency (timeliness), the degree of completeness and format, how well the information "hangs together" (coherence), how accessible it is, how it can be combined with other information (compatibility), how secure it is and whether it can be verified as being true (validity)".

In the literature we can also find numerous examples of studies that focus on a certain aspect of web resources, usability being one of the features that has received most attention in recent years (Corry, Frick \& Hansen, 1997; Colmes, 2002; Spool, 1999).

A number of indicators and models for evaluating websites associated to a particular domain have also been developed, as is the case for libraries (Chao, 2002; Clausen, 1999; Olsina et al., 1999), business organisations (Barnes \& Vidgen, 2001, 2002; Miranda González \& Bañegil Palacios, 2004) or medical information (Berstam et al., 2005; Jadad \& Cagliardi, 1998; Kim et al., 1999; Haddow, 2003).

\section{Methodology}


To conduct our research we decided to apply a varied, complementary methodology that would enable us to analyse indicators of the quality of the visibility of the information on research offered on Spanish university websites. Our study was conducted in a number of different stages: gathering criteria by analysing the scientific literature, analysis of their usefulness for the study to be carried out, brainstorming sessions to select the most suitable ones, analysis of the websites according to the template that had been designed ad hoc, data tabulation and analysis (both descriptive and comparative, as well as $\boldsymbol{S}$ trengths, Weaknesses, $\boldsymbol{O}$ pportunities, and Threats analysis: SWOT analysis).

\subsection{Data sources: proposed criteria}

"Information quality can have different evaluative dimensions depending on the research approach undertaken or the sphere of investigation" (Sellitto \& Burgess, 2005), thus, the criteria and indicators we use to determine the quality of a website will basically depend on both the information we want to obtain from such an analysis and on the characteristics of the websites being studied. Therefore, from all the criteria put forward in the literature we must select the ones that can be of most use to us.

The following criteria and indicators were gathered from the scientific literature on criteria for the quality of websites, as well as from the findings from another research project funded by the Spanish Ministry of Education and Science to study the visibility of research in Spanish universities (Pinto, M., 2003; Pinto, M. et al., 2005). Seven main criteria were selected, taking into account the fact that the foremost aspect to be evaluated in this work was the dissemination of information about the EHEA; the other criteria were therefore dealt with to a lesser extent and analysed in less depth.

a) VISIBILITY OF INFORMATION 
The purpose of this criterion is to determine the visibility of the website dedicated to the EHEA of each university, that is to say, to find out whether it is easily visible from the home page of the university website. This is a very significant criterion because, at the present time when we on the verge of implementing European convergence as far as higher education is concerned, it is important to have access to high quality information about this process and about the new model of education. Universities must facilitate access to this information, since they are involved in the process and the EHEA affects the whole university community, that is, both teaching staff and students, as well as all the other members of staff working at the university. Such valuable information must therefore be readily available and anyone wishing to search for it must be able to find it without any kind of difficulties.

To measure this criterion we used indicators such as the level from which the EHEA web is accessed within the university, whether it is listed in the table of contents of the university, whether the information is arranged in a suitable manner, whether there is a search engine on the university home page that enables us to locate information about the EHEA and whether these resources have Metadata that make it easier to identify and search for them.

\section{b) AUTHORITY}

The authority of a work, no matter what its nature, is a vitally important piece of data that we must know and, therefore, it must be easily identifiable. The presence of this kind of information on a website is essential because authority is frequently taken as a criterion to measure the quality and credibility of a resource, both on traditional and digital media. The absence of this information can be considered to be a weakness and may well mean that a resource is not seen as being valid due to the fact that we do not know who is responsible for its content.

\section{c) UPDATENESS}

One of the advantages web resources have over traditional supports is that they can be modified easily and can therefore be kept up to date. In a world where information is power and the more 
up-to-date that information is, the more it is worth, it is obvious that an obsolete resource that is not regularly updated is worthless. In the case of websites it is vital to keep them updated since, because they are based on hypertext, if the links are not updated they can become broken or stop working, which turns the resource into something that is of no use to anyone. Checking the links on a website regularly is a highly recommendable practice in order to keep a resource properly updated.

In addition to keeping a check on the links on the site, it is also necessary to incorporate information about current affairs, announcements, and so forth, together with all kinds of information resources that people will find useful once they know they are there. Thus, users will not need to access other sources in order to obtain up-to-date information.

One indicator that was used in this study is the presence of the date the resource was last revised, which allows us to know how up-to-date the information is; unfortunately this is a good practice that is not as widely employed as it should be.

\section{d) ACCESSIBILITY}

The accessibility criterion attempts to determine how easy it is for users to consult the website regardless of the browser or OS they are using, their physical condition or their language, as well as examining the degree of accessibility for users with some disability. According to the WAI, "Web accessibility means that people with disabilities can use the Web. More specifically, Web accessibility means that people with disabilities can perceive, understand, navigate, and interact with the Web, and that they can contribute to the Web". The W3C (1999) has proposed a checklist for evaluating the degree of accessibility of a web resource that includes aspects such as the frames, scripts, presentation of the information, navigation, and so forth.

We will focus on designs that are compatible with different browsers, compliance with the WAI recommendations, and the existence of printable versions, different languages and navigation aids.

\section{e) CORRECTNESS AND COMPLETENESS}


In a web resource, the scope of the resource, its coverage, its reliability and whether it offers the most complete and thorough information possible are all factors that must be taken into consideration. To be able to analyse and evaluate these aspects, we have to know what information a resource should offer but fails to do so. This is the most important criterion in this study, since our main aim is to analyse what information about EHEA is disseminated in our public universities. To this end, we determined what information or what resources ought to be provided on a website dedicated to the EHEA and a series of indicators were proposed with which to observe whether the website under study offered access to each type of information resource. The resources that we considered in our study were grouped under the following headings: general information, regulations, congresses, programmes and announcements, and specific indicators were developed to see what information they offer in relation to the above mentioned aspects.

\section{f) QUALITY ASSESSMENT}

W3C (1997) argued that the term 'quality', applied to information on the Internet, is a goal that involves a continuous process of planning, analysis, design, implementation, promotion and innovation in order to ensure that the information covers the users' needs as far as contents and interface are concerned. But this objective is anything but easy to achieve and not everyone who publishes material on the Internet places quality among their highest priorities.

Thus, the website's policy with regard to quality and the importance given to it by those responsible for managing the site are factors that are also analysed. In this study importance was granted to whether or not the quality policy of the resource was stated, the existence of a suggestion box that allows the user to interact with the site and whether surveys are carried out to determine users' degree of satisfaction with the website.

\section{g) NAVEGABILITY}

According to Marqués Graels (2003), the navigation systems and the way interactions with users are managed will to a large extent determine how easy and user-friendly a site is. The 
following aspects should be taken into account when evaluating it: the presence of sitemaps, adequate navigation systems, speed and reliability. This criterion, thus, concerns the ease with which someone can move around a website while knowing "where they are", as well as how to get to the information they are looking for, at all times. Owing to the quantitative nature and aims of this study, only three aspects were considered in the analysis, that is, the contents menu, the consistent use of terminology and the existence of navigation buttons.

\subsection{Data collection and processing}

The universe used in the study consisted of all the Spanish public universities - in all, a total of 48 universities. The list of Spanish public university websites was obtained from the Spanish Ministry of Education and Science (http://www.mec.es) and was checked against the one posted on the Conference of Rectors of Spanish Universities website (http://www.crue.org). In fact, we were only able to analyse 45 of the web resources because the universities of Cordoba, La Rioja and Girona do not have a website about the EHEA.

A set of qualitative and quantitative indicators were defined to obtain our results. Qualitative indicators were adapted depending on the context being analysed. We started out by conducting a study of the documents considered to be fundamental in the European Higher Education Area, which gave us a clear view of the "hot" points of European convergence, as well as the terminology that was utilised.

The tool we used to collect data was a template that included the seven criteria selected for evaluating the quality of these web resources; these criteria were further broken down until a total of 68 subcriteria and indicators was reached.

A pre-test was run in some of the universities that offered most data in order to see whether more indicators were required. This was carried out by different researchers and then a brainstorming session was held to readapt the work sheet. Additionally, this sheet had already been used in 2003 in another study conducted to investigate the visibility of the diffusion of universities, as part of a Studies and Analysis project conducted for the Spanish Ministry of 
Education and Science. This meant that we already knew that it was suitable for the task at hand and it only had to be adapted to the EHEA context.

As a step prior to use of the template, we proceeded to assign weights to the subcriteria. Each indicator used in the study had its own specific weight, since more importance was granted to some aspects than to others. "The weighted results serve to accentuate the differences indicated above in the direction of user priorities. Each respondent's site rating for a question is multiplied by the importance attached to it by the individual. [...] the total weighted score gives some indication of this" (Barnes \& Vidgen, 2002). The weighting of each criterion was assigned on the basis of our opinions: after a brainstorming session, we decided which criteria were the most important and which were less so. We rated them from 1 to 2,1 being a normal criterion and 2 reflecting a more important criterion. The most important criteria were found to be diffusion and visibility.

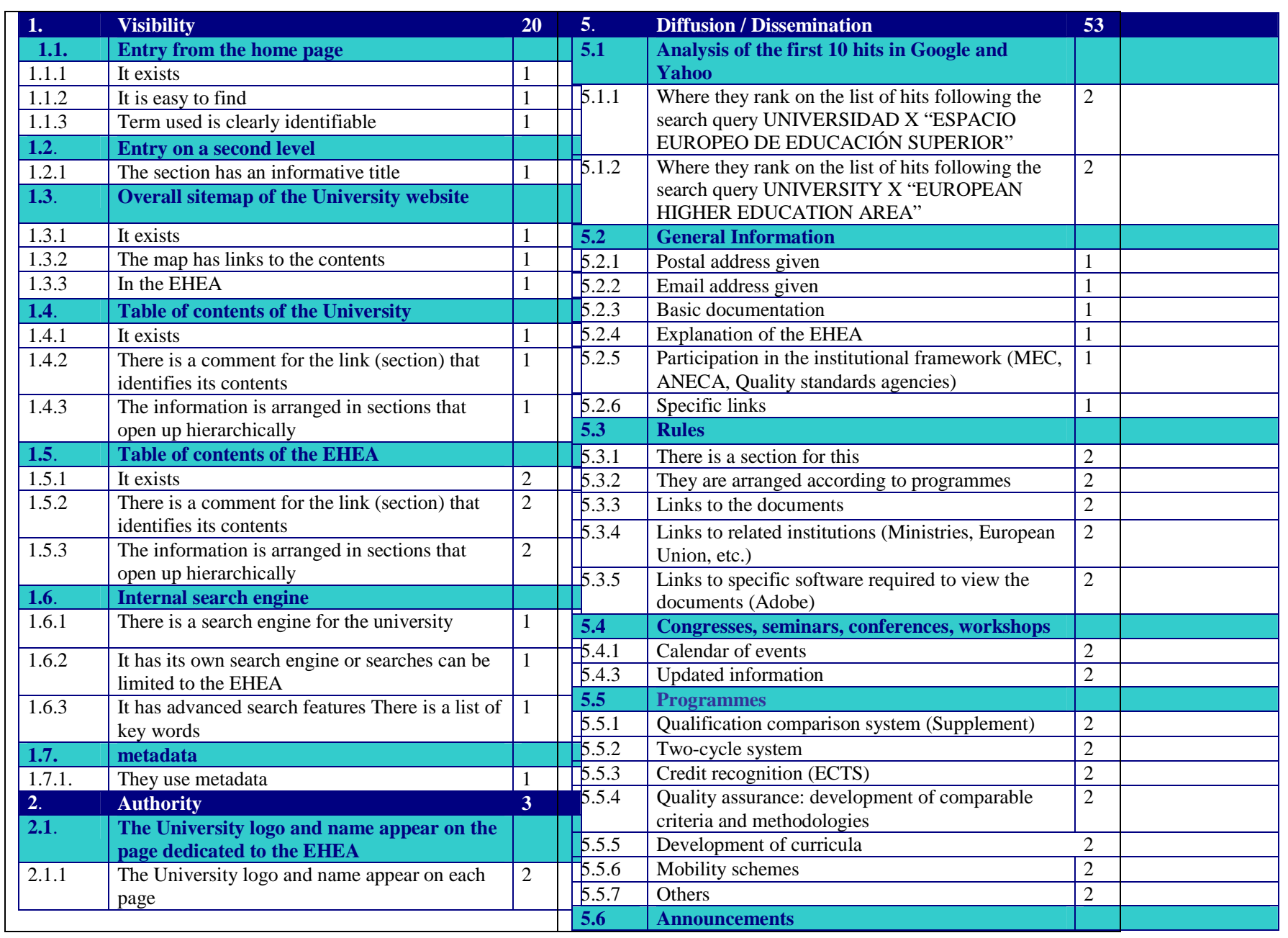




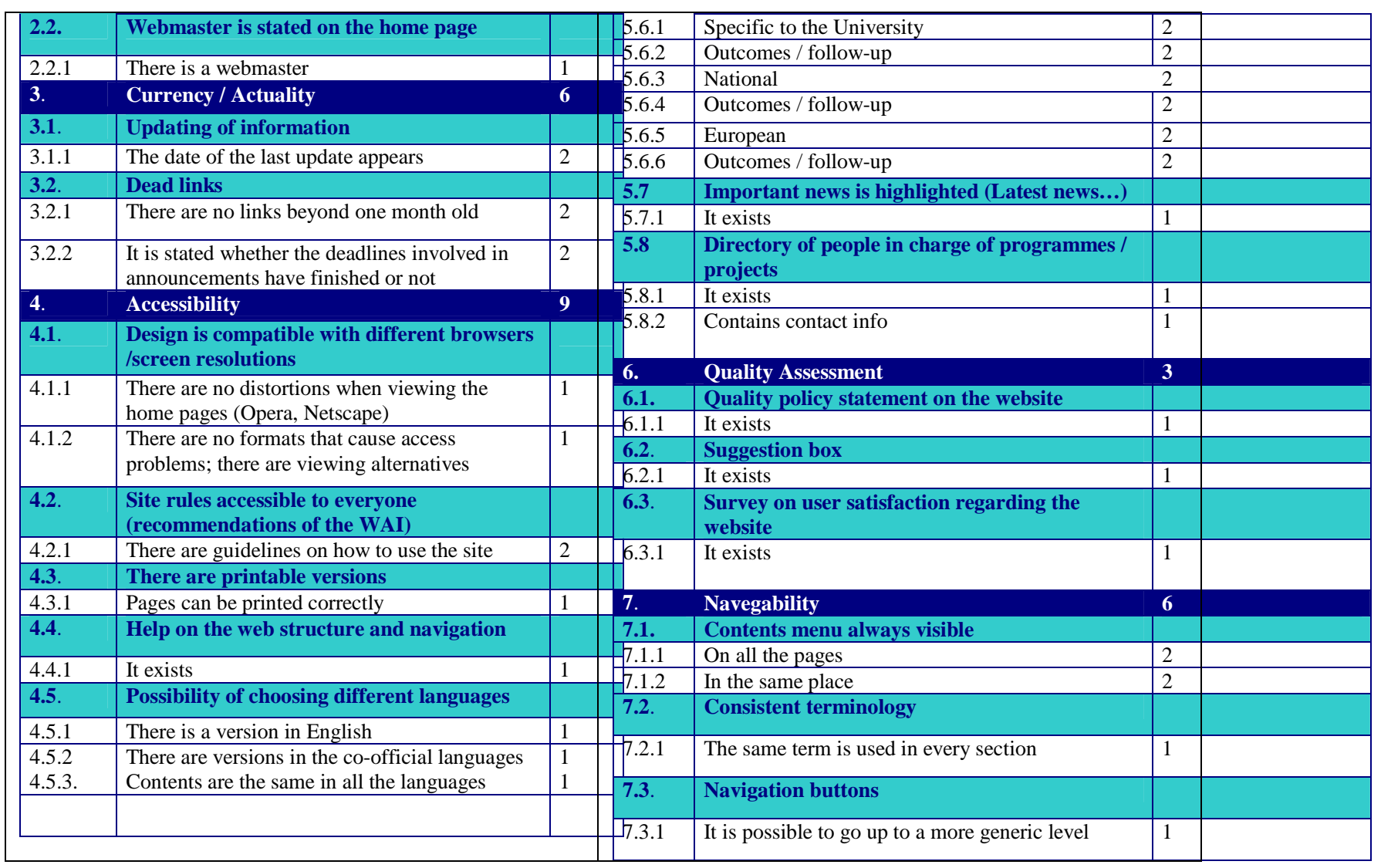

The process of collecting data was performed manually during the second fortnight in May 2006. The results obtained were always verified, on the basis of simultaneous evaluations by the authors of the study, to confirm the legitimacy of the evaluation. Information was gathered by visiting each of the university websites (if they existed) in order to search for the webpage dedicated to the European Higher Education Area. At universities that did not have a direct link to such websites, we used the search facility that most of them offer. The terms we chose to carry out the searches were: "Espacio Europeo de Educación Superior", "Espacio Europeo de Enseñanza Superior", "Convergencia Europea", "Armonización Europea". In the case of universities located in areas that have a second official language, these search terms were translated.

Catalan/Valencian: Espai Europeu d'Educació Superior, Espai Europeu d'Ensenyament Superior, Convergència Europea, Harmonització Europea

Galician: Espazo Europeo de Educación Superior, Espazo Europeo de Ensino Superior, Convergencia Europea, Armonización Europea 
Basque: Espazioa Europar Hezkuntza Goikoa, Espazioa Europar Irakaskuntza Goikoa, Bateratasuna Europarra, Harmonizazio Europarra.

If any universities had pages concerning the EHEA in other languages, they were all visited to gather the relevant information, and the corresponding box was checked to show that the information is the same (or not) in each language.

For universities in which it was not possible to find a specific page about the EHEA, a search was carried out by programmes to see whether they are assigned to other units or services. If this were the case, a note was added to the evaluation sheet.

Drawing up SWOT analysis-type reports for each university was equally important for the final analysis. These reports contained the main strong and weak points found in each case, together with suggested improvements.

Data was processed in the following way:

- Since the process of collecting data using templates was based on affirmative or negative answers to the criteria (a score of 1 is assigned when it is positive and 0 when it is negative), we calculated the total number of "right" answers (i.e. how many criteria had positive answers) for each of the subcriteria: "the proposed categories use the affirmative response assessment as an evaluative process - a process that appears to have been easily implemented and utilised amongst previously discussed evaluation systems" (Sellitto \& Burgess, 2005). This allowed us to see how many criteria were fulfilled by each of the universities. The total number of criteria is 68 , and from these data we were able to calculate the percentage of correct answers.

- Based on these percentages, we then assigned a numerical value between 1 and 5 in order to obtain a rating, as follows:

\begin{tabular}{|l|l|l|}
\hline Percentage & Score & Rating \\
\hline From $0 \%$ to $20 \%$ & 1 & Not acceptable (NA) \\
\hline From $21 \%$ to $40 \%$ & 2 & Poor (P) \\
\hline From $41 \%$ to $60 \%$ & 3 & Acceptable (A) \\
\hline From $61 \%$ to $80 \%$ & 4 & Good (G) \\
\hline From $81 \%$ to $100 \%$ & 5 & Very good (VG) \\
\hline
\end{tabular}


This percentage was calculated at an overall university level and for each of the seven criteria.

The official acronyms for the universities (as they appear in the following table) are used in the graphs and tables:

\begin{tabular}{|l|l|l|l|}
\hline UNIVERSITY & ACRONYM & UNIVERSITY & ACRONYM \\
\hline A Coruña & udc & Málaga & uma \\
\hline Alcalá de Henares & uah & Miguel Hernández & umh \\
\hline Alicante & ua & Murcia & Um \\
\hline Almeria & ual & UNED & uned \\
\hline Aut. Barcelona & uab & Oviedo & uniovi \\
\hline Aut. Madrid & uam & Pablo de Olavide & upo \\
\hline Barcelona & ub & País Vasco & ehu \\
\hline Burgos & ubu & Pol. Cartagena & upct \\
\hline Cádiz & uca & Pol.Cataluña & upc \\
\hline Cantabria & unican & Pol. Madrid & upm \\
\hline Carlos III & uc3m & Pol. Valencia & upv \\
\hline Cast. Mancha & uclm & Pompeu Fabra & upf \\
\hline Complutense & ucm & Pública de Navarra & unavarra \\
\hline Extremadura & unex & Rey Juan Carlos I & urjc \\
\hline Granada & ugr & Rovira I Virgili & urv \\
\hline Huelva & uhu & Salamanca & Usal \\
\hline & & Sant. De & \\
Iles Baleares & uib & Compostela & Usc \\
\hline Jaén & ujaen & Sevilla & Us \\
\hline Jaume I & uji & Valencia & Uv \\
\hline La Laguna & ull & Valladolid & Uva \\
\hline Las Palmas & ulpgc & Vigo & Uvigo \\
\hline León & unileon & Zaragoza & Unizar \\
\hline Lleida & udl & & \\
\hline
\end{tabular}

\section{Discussion of results}

Since the objective pursued in this research was to obtain a global view of the situation in which Spanish public universities find themselves as regards dissemination of information about the EHEA, on presenting our findings we decided to arrange them according to the seven criteria used to conduct the study. This would provide us with a vision of the state of the art in Spanish public universities in each of the aspects analysed by offering us an overall average rating for 
the universities as a whole; at the same time it would highlight the best practices and show which universities need to improve in each of the seven criteria.

Global findings are shown at the end of this section; these results include the rating obtained by each university on each criterion, as well as the total score, which is the result of adding up the partial scores. Observing these data enables us to obtain a view of the strengths and weak points of each university, although a detailed analysis lies beyond the scope of this paper.

\section{Visibility}

The results obtained on this criterion, according to the indicators that we proposed to evaluate visibility, are quite modest and the mean score did not even reach a "pass mark" - 9.1 out of a possible 20 points. Most of the universities were rated as Acceptable $(33,73.4 \%)$, that is to say, they fall within the range of between 8 and 12 points, although with values that tended to be low. Of all the universities analysed, only one (2.2\%) - Alcalá de Henares - obtained a rating of Good, 9 universities (20\%) were rated as being Regular and 2 universities (4.4\%) were given a rating of Not acceptable.

\begin{tabular}{|l|l|l|l|}
\hline RATING & FREQUENCY & PERCENTAGE & UNIVERSITIES \\
\hline G & 1 & $2.22 \%$ & Uah \\
\hline A & 33 & $73.4 \%$ & $\begin{array}{l}\text { Upc, ub, uniovi, ehu, us, uab, ual, upo, uca, uned, } \\
\text { uam, ubu, uclm, ucm, uric, unileon, uma, udl, ua, } \\
\text { uva, uv, unex, ull, umh, urv, upct, upv, uvigo, ull, } \\
\text { um, unizar, uc3m }\end{array}$ \\
\hline P & 9 & $20 \%$ & Udc, upm, usal, ugr, usc, uhu, unican, ujaen, uib \\
\hline NA & 2 & $4.44 \%$ & Unavarra, ulpgc \\
\hline
\end{tabular}

Details concerning visibility can be better appreciated by analysing each of the seven subcriteria used in our study:

The easiest way to access the resource is from the home page on the university website; it is also a way to draw visitors' / users' attention to such an important topic, as is the EHEA. In general terms this indicator is fulfilled by the websites: in 26 universities (57.8\%) this shortcut exists and is easy to find and identify; access was not possible from the home page in only 5 cases $(11.1 \%)$. 
As regards entry at a second level, the findings were intermediate: 25 universities (55.6\%) have a section on their home page with a name that is descriptive enough to make users think that they can find information about the EHEA in that section.

Only the Universidad de Cádiz had a sitemap with links to the contents - something that is quite disappointing because this kind of tool makes it much simpler to locate information and helps us to find our way around a website. This is an important weak point that affects $98 \%$ of the universities.

Another way to allow easy access to the information is to offer appropriately organised tables of contents. These tables are present on the home pages of all the Spanish universities except two, and they are also quite well structured. Nevertheless, on the websites specifically dedicated to the EHEA, 5 universities did not have this table and, in general, they were more poorly organised and did not have comments in the links (29 universities, 64\%).

Although the other aspects that were analysed concerned browsing to locate information, the two remaining subcriteria referred to the actual searching, that is, the procedure which allows information to be found quickly and with precision. First, it was found that 93.5 of the universities had an internal search engine and that only the search engines at 3 universities (6.7\%) offered advanced search functions and can limit it to the resource about the EHEA; these options were not offered by most of the other universities. Second, it was found that all the universities had inserted metadata in these websites, which made it easier to describe and identify them, as well as to retrieve them in search engines.

In sum, we can say that the main weaknesses were the absence of sitemaps on the university home pages, the functioning of the search engine, and the characteristics of the tables of contents in the resources about the EHEA.

The scores obtained on visibility are shown in the following graph: 


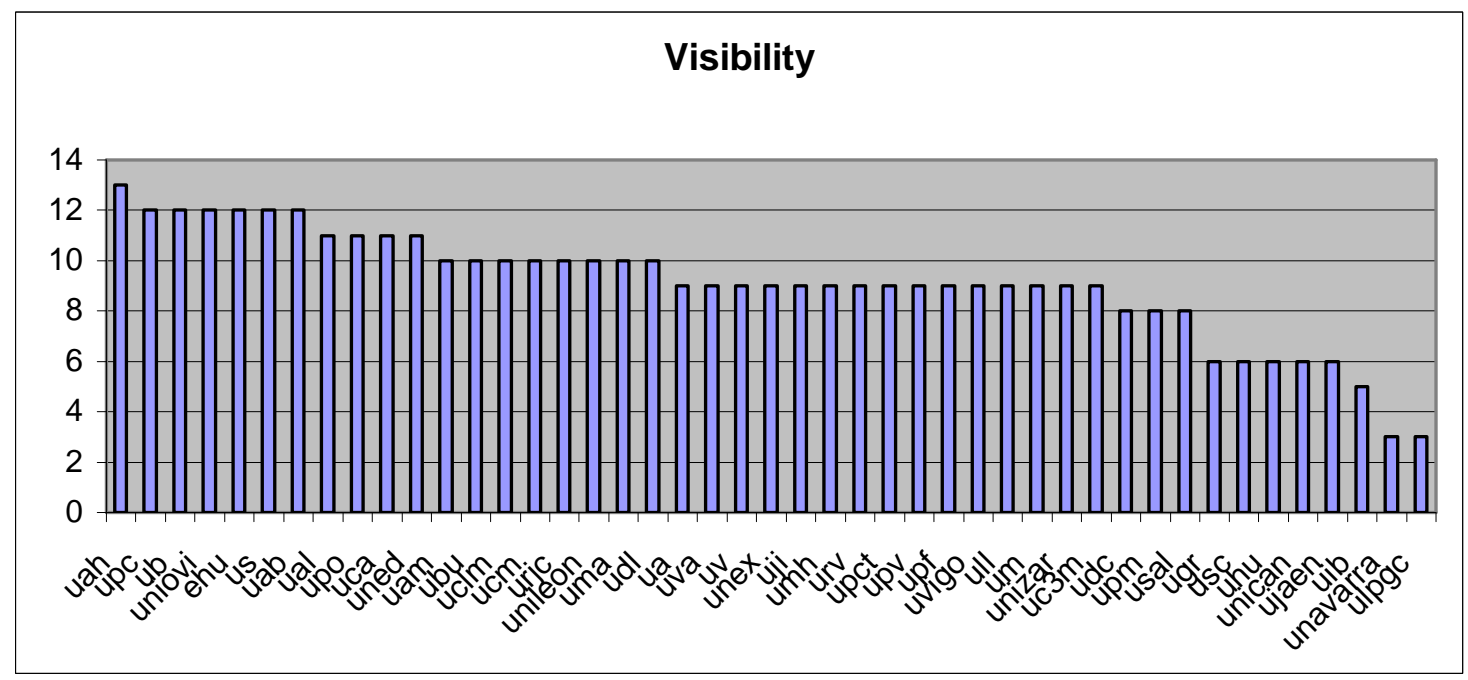

\section{Authority}

Generally speaking, authority is a feature that Spanish public universities dedicate quite a lot of attention to, with a mean score of 2.1 out of a possible 3 points and 40 universities (89\%) were rated as good or very good.

The university logo and name appear in 40 cases $(89 \%)$, thus leaving no doubts whatsoever about which organisation is responsible for the resource.

Details about how to contact the webmaster, however, did not appear very often and only 13 universities (29\%) provided this information on their EHEA websites. This is one of the points that many universities ought to work to improve because this information enables users to contact those responsible for running the resource should they detect some mistake or problem. The table below shows the results for each university:

\begin{tabular}{|l|l|l|l|}
\hline RATING & FREQUENCY & PERCENTAGE & UNIVERSITIES \\
\hline VG & 12 & $26.67 \%$ & $\begin{array}{l}\text { Upc, ub, uniovi, unex, ugr, ehu, us, ubu, uclm, } \\
\text { uvigo, uib, ujaen }\end{array}$ \\
\hline G & 28 & & $\begin{array}{l}\text { Ua, uva, uv, uji, udc, umh, uab, upo, urv, usc, uca, } \\
\text { uptc, ucm, uah, hpv, upm, upf, ull, uhu, unavarra, } \\
\text { urjc, uned, unican, unileon, uma, unizar, udl, ulpgc }\end{array}$ \\
\hline P & 2 & $62.22 \%$ & Ual, um \\
\hline NA & 3 & $6.44 \%$ & Uam, uc3m, usal \\
\hline
\end{tabular}




\section{Updating and currency}

Two aspects were taken into account in rating this criterion: whether the date of the last update was stated on the page, which 12 universities (26.7\%) fulfilled, and the existence of dead links, which were rated depending on the announcements and whether the deadlines have finished or not. It must be said that most of them did not include dead links, but only 15 (33.3\%) stated whether the deadlines have finished or not.

The mean score on this criterion was 2.6 out of 6 , which means that this is an aspect that needs quite a lot of improvement, especially as regards indicating the last update and whether the deadlines involved in the announcements have finished or not.

The following table shows the ratings obtained by each university:

\begin{tabular}{|l|c|c|l|}
\hline RATING & FREQUENCY & PERCENTAGE & UNIVERSITIES \\
\hline VG & 3 & $6.67 \%$ & Unex, uam, uca \\
\hline G & 12 & $26.67 \%$ & $\begin{array}{l}\text { Ua, uva, upc, ub, uji, us, uab, uah, upv, uib, ujaen, } \\
\text { usal }\end{array}$ \\
\hline P & 25 & $55.56 \%$ & $\begin{array}{l}\text { Uv, uniovi, ual, ugr, ehu, umh, upo, ubu, usc, upct, } \\
\text { uclm, ucm, upf, uvigo, ull, um, uhu, urje, uned, } \\
\text { unican, unileon, uma, unizar, uc3m, udl }\end{array}$ \\
\hline NA & 5 & $11.11 \%$ & Udc, uvr, upm, unavarra, ulpgc \\
\hline
\end{tabular}

\section{Accessibility}

Results on accessibility were quite poor, the mean score being 3.6 out of 9 , with $87 \%$ of universities lying somewhere between Acceptable and Regular.

\begin{tabular}{|l|c|c|l|}
\hline RATING & FREQUENCY & PERCENTAGE & UNIVERSITIES \\
\hline G & 4 & $8.9 \%$ & Unex, us, usc, urjc \\
\hline A & 19 & $42.22 \%$ & $\begin{array}{l}\text { Ua, upc, ub, udc, umh, uab, uah, um, unavarra, } \\
\text { uniovi, uji, ehu, urv, ubu, uca, upv, upf, uin, unizar }\end{array}$ \\
\hline P & 21 & $46.66 \%$ & $\begin{array}{l}\text { Uva, uv, uam, upo, upct, ucm, uvigo, ujaen, udl, } \\
\text { ulpgc, ugr, uclm, upm, ull, uhu, uned, unican, } \\
\text { unileon, uma, uc3m, usal }\end{array}$ \\
\hline NA & 1 & $2.22 \%$ & Ual \\
\hline
\end{tabular}

On analysing the 5 subcriteria, some of the key points behind these findings can be observed.

In the university resources about the EHEA there are no formats that hinder access (Flash, for instance), except at the universities of the País Vasco and Vigo, but only 7 universities (15.6\%) 
offered pages that were free of distortions when viewing the home page regardless of the browser that was used. This is an important element because, despite being hugely popular, not everyone uses Internet Explorer.

Only 9 universities (20\%) state compliance with the WAI regulations, something that is essential in the web environment because all kinds of users have to be taken into account.

Printable versions of the information were offered by $89 \%$ of the universities.

Help is an important element that enables users to solve their problems and to take maximum advantage of the resource. Despite its valuable, however, only 9 universities (20\%) offer help facilities.

Another aspect that was analysed was whether it was possible to consult the website in different languages. Sites were rated on whether, in addition to the Spanish version, there were versions in English (due to its being the language with the greatest impact in the university environment) and in the other co-official languages that exist in Spain. Whether or not the information coincided in each of the languages was another factor that was also taken into account. Findings showed that there were versions in different languages, although their contents did not usually coincide.

On breaking this criterion down further, we found that the main deficits with regard to Accessibility involve navigation aids and the absence of a statement of compliance with WAI regulations; the other aspects were considered to be acceptable.

\section{Correctness and completeness}

This is the criterion we granted most importance to and it is also the one that was analysed in the greatest depth, due to the fact that the aim of our study was to evaluate what information each university offered about the EHEA. Really, no matter how important the other aspects might be, if the site fails in the information it offers, we can say that the resource as a whole is a failure.

As in other criteria, in this case Spanish public universities scored close to the "pass mark", that is, around half the total number of points ( 27.6 out of $53 ; 5.2$ out of 10 ). Results showed that 
$42.2 \%$ of the universities were rated as acceptable and the rest were split more or less equally between either good or very good (26.7\%), on the one hand, and regular or not acceptable (31\%), on the other.

\begin{tabular}{|l|c|c|l|}
\hline RATING & FREQUENCY & PERCENTAGE & UNIVERSITIES \\
\hline VG & 4 & $8.89 \%$ & Ua, uva, uv, ual \\
\hline G & 8 & $17.78 \%$ & Ugr, uniovi, upc, ub, upo, uji, udc, upm \\
\hline A & 19 & $42.22 \%$ & $\begin{array}{l}\text { Ehu, urv, upct, umh, unex, usc, ull, uam, uclm, upf, } \\
\text { unavarra, uhu, uab, uca, ucm, us, ubu, upv, univgo }\end{array}$ \\
\hline P & 13 & $28.89 \%$ & $\begin{array}{l}\text { Uib, unileon, unican, uma, uc3m, um, uned, ujaen, } \\
\text { urjc, ulpgc, uah, udl, unizar }\end{array}$ \\
\hline NA & 1 & $2.22 \%$ & Usal \\
\hline
\end{tabular}

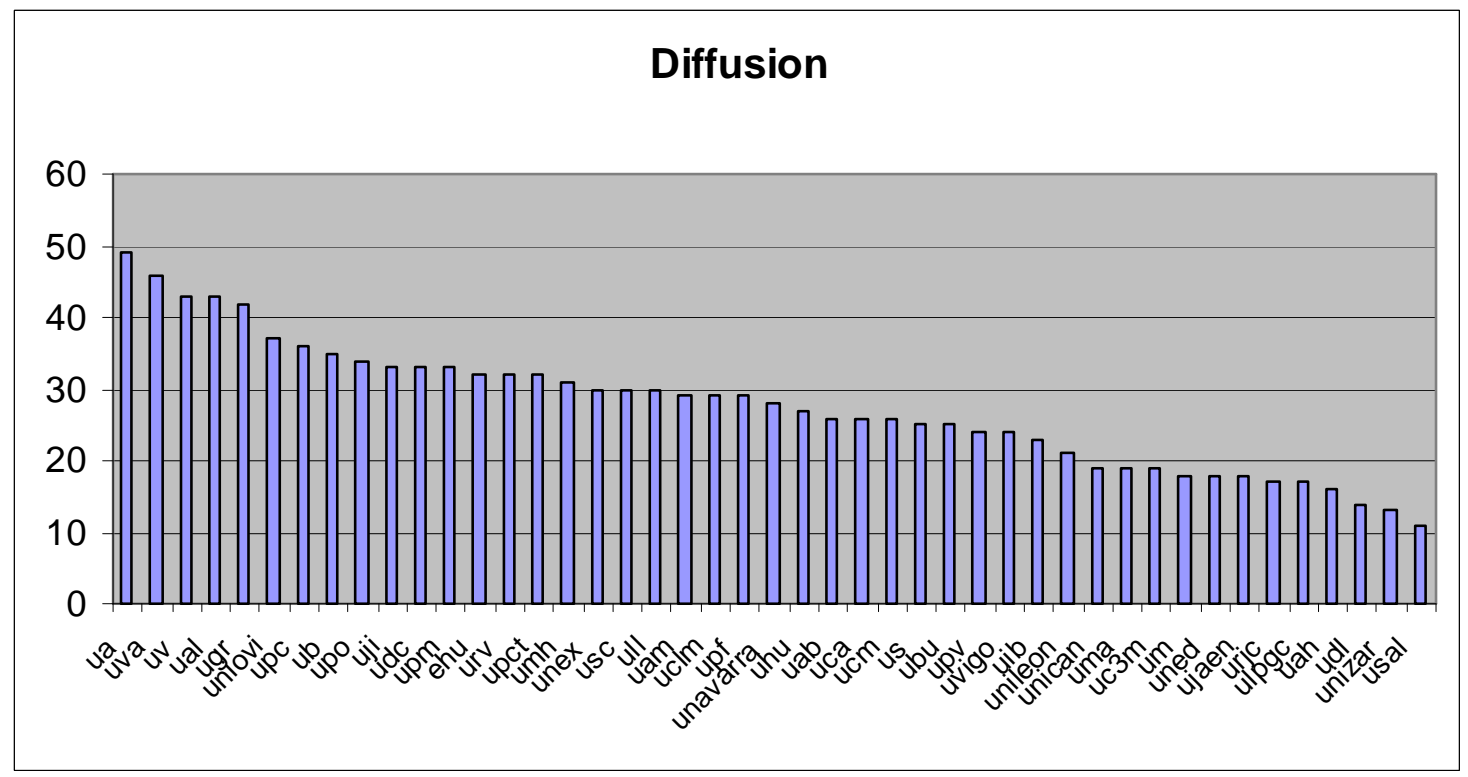

We used 8 subcriteria, with their corresponding indicators, to evaluate the diffusion of the information about the EHEA. First of all, we tested whether searching in Google or in Yahoo for information about the EHEA associated with each university, both in Spanish and in English, returned links to these resources and, indeed, this was the case for all the universities.

We also analysed whether the resources provided general information about the EHEA, such as postal addresses, email addresses, basic documentation, explanation of the EHEA, participation in the institutional framework and specific links. Good scores were obtained on this aspect, with a mean rating of 4.8 out of 6 for this criterion. 
One especially important type of information is the regulations governing the EHEA; we found that all the websites had a section dedicated to this kind of data and, in general, they were well structured and contained relevant links. The mean score in this section was 6.27 out of a total of 10.

As the EHEA is still in the embryonic stage, numerous congresses and workshops are held in order to try to iron out the differences between different postures, to discuss the way it is to be implemented or to exchange impressions about how we should adapt to this new educational framework. This is why we also examined whether there was a calendar of forthcoming congresses, which did exist in most cases (29 universities, 64\%), and whether it was kept up-todate, which was only the case in 10 universities (22.2\%).

We also studied whether the resources offered information about the different programmes of education associated to the EHEA, such as the development of curricula, mobility schemes, credit recognition, and so forth. In general terms, the websites do offer this information, although it is usually quite incomplete: the mean score was 6.1 out of 14 and only 4 universities (8.9\%) provided information on all the aspects used in this subcriteria.

On analysing the follow-up of the different announcements related to the EHEA, we saw that the results were not particularly good - the mean score being 4.1 out of 12 . There were 8 universities $(17.6 \%)$ that did not include this information and those that did include it did not usually specify the results or the status of those announcements, that is, whether the deadline has finished or not.

We wanted to know whether important items were highlighted in some way in order to draw users' attention to them, and we found that in $62.2 \%$ of cases this was not the case.

Lastly, we investigated whether these resources included a directory of people in charge of EHEA-related projects or programmes and whether contact information was given. Such a tool was not offered by 39 universities, thus making it one of the features that must be improved.

The following table shows the scores obtained by each university on the criterion as a whole and on each subcriterion, ordered from the highest to the lowest scores. 


\begin{tabular}{|c|c|c|c|c|c|c|c|c|c|}
\hline Universities & $\begin{array}{l}\text { Tota } \\
\text { l }\end{array}$ & $\begin{array}{l}5 . \\
1\end{array}$ & \begin{tabular}{|l|}
5. \\
2
\end{tabular} & $\begin{array}{l}5 . \\
3\end{array}$ & \begin{tabular}{|l|}
5. \\
4 \\
\end{tabular} & \begin{tabular}{|l|}
5. \\
5
\end{tabular} & \begin{tabular}{|l|}
5. \\
6
\end{tabular} & $\begin{array}{l}5 . \\
7\end{array}$ & \begin{tabular}{|l|}
5. \\
8
\end{tabular} \\
\hline $\begin{array}{l}\text { Maximum } \\
\text { possible score }\end{array}$ & 53 & 4 & 6 & 10 & 4 & 14 & 12 & 1 & 2 \\
\hline $\mathrm{Ua}$ & 49 & 4 & 6 & 8 & 4 & 14 & 12 & 1 & 0 \\
\hline Uva & 46 & 4 & 6 & 6 & 4 & 14 & 10 & 0 & 2 \\
\hline Ual & 43 & 4 & 6 & 8 & 4 & 6 & 12 & 1 & 2 \\
\hline Uv & 43 & 4 & 6 & 6 & 4 & 12 & 10 & 1 & 0 \\
\hline Ugr & 42 & 4 & 3 & 8 & 4 & 10 & 10 & 1 & 2 \\
\hline Uniovi & 37 & 4 & 5 & 8 & 4 & 14 & 2 & 0 & 0 \\
\hline Upc & 36 & 4 & 5 & 6 & 4 & 8 & 8 & 1 & 0 \\
\hline $\mathrm{Ub}$ & 35 & 4 & 4 & 6 & 4 & 10 & 6 & 1 & 0 \\
\hline Upo & 34 & 4 & 6 & 6 & 4 & 8 & 6 & 0 & 0 \\
\hline $\mathrm{Udc}$ & 33 & 4 & 4 & 8 & 2 & 8 & 6 & 1 & 0 \\
\hline Uji & 33 & 4 & 6 & 6 & 0 & 12 & 4 & 1 & 0 \\
\hline Upm & 33 & 4 & 5 & 8 & 2 & 8 & 6 & 0 & 0 \\
\hline Ehu & 32 & 4 & 4 & 6 & 2 & 8 & 8 & 0 & 0 \\
\hline Upct & 32 & 4 & 4 & 8 & 2 & 10 & 4 & 0 & 0 \\
\hline Urv & 32 & 4 & 6 & 6 & 2 & 8 & 6 & 0 & 0 \\
\hline Umh & 31 & 4 & 3 & 6 & 4 & 14 & 0 & 0 & 0 \\
\hline Unex & 30 & 4 & 4 & 6 & 4 & 6 & 4 & 1 & 1 \\
\hline Ull & 30 & 4 & 4 & 6 & 0 & 10 & 4 & 0 & 2 \\
\hline Usc & 30 & 4 & 5 & 8 & 2 & 10 & 0 & 1 & 0 \\
\hline Uam & 29 & 4 & 6 & 8 & 4 & 2 & 4 & 1 & 0 \\
\hline Uclm & 29 & 4 & 6 & 8 & 0 & 6 & 2 & 1 & 2 \\
\hline Upf & 29 & 4 & 5 & 4 & 4 & 8 & 4 & 0 & 0 \\
\hline Unavarra & 28 & 4 & 2 & 2 & 4 & 12 & 4 & 0 & 0 \\
\hline Uhu & 27 & 4 & 5 & 6 & 4 & 6 & 2 & 0 & 0 \\
\hline $\mathrm{Uab}$ & 26 & 4 & 6 & 8 & 0 & 4 & 4 & 0 & 0 \\
\hline Uca & 26 & 4 & 2 & 6 & 2 & 8 & 4 & 0 & 0 \\
\hline $\mathrm{Ucm}$ & 26 & 4 & 6 & 6 & 2 & 6 & 2 & 0 & 0 \\
\hline Ubu & 25 & 4 & 3 & 6 & 0 & 6 & 6 & 0 & 0 \\
\hline Us & 25 & 4 & 6 & 6 & 2 & 0 & 6 & 1 & 0 \\
\hline Upv & 24 & 4 & 4 & 6 & 0 & 6 & 4 & 0 & 0 \\
\hline Uvigo & 24 & 4 & 6 & 6 & 0 & 0 & 8 & 0 & 0 \\
\hline Uib & 23 & 4 & 4 & 6 & 4 & 2 & 2 & 1 & 0 \\
\hline $\mathrm{Um}$ & 22 & 2 & 5 & 10 & 2 & 2 & 0 & 1 & 0 \\
\hline Unileon & 21 & 4 & 5 & 6 & 0 & 2 & 4 & 0 & 0 \\
\hline Unican & 19 & 4 & 3 & 8 & 0 & 2 & 2 & 0 & 0 \\
\hline $\mathrm{Uc} 3 \mathrm{~m}$ & 19 & 4 & 2 & 8 & 4 & 0 & 0 & 1 & 0 \\
\hline Uma & 19 & 4 & 5 & 6 & 4 & 0 & 0 & 0 & 0 \\
\hline Ujaen & 18 & 4 & 4 & 4 & 4 & 2 & 0 & 0 & 0 \\
\hline Uned & 18 & 4 & 3 & 6 & 0 & 2 & 2 & 1 & 0 \\
\hline Ulpgc & 17 & 4 & 1 & 4 & 0 & 8 & 0 & 0 & 0 \\
\hline Urjc & 17 & 4 & 5 & 8 & 0 & 0 & 0 & 0 & 0 \\
\hline Uah & 16 & 4 & 6 & 4 & 0 & 0 & 2 & 0 & 0 \\
\hline
\end{tabular}




\begin{tabular}{|l|r|r|r|r|r|r|r|r|r|} 
Udl & 14 & 4 & 4 & 6 & 0 & 0 & 0 & 0 & 0 \\
\hline Unizar & 13 & 4 & 3 & 2 & 0 & 2 & 2 & 0 & 0 \\
\hline Usal & 11 & 4 & 3 & 2 & 0 & 0 & 2 & 0 & 0 \\
\hline
\end{tabular}

To sum up we could say that the weak points of this criterion were related to information about programmes, announcements, important information and the directory of people in charge of different areas. In contrast, strong points were visibility in search engines, general information and regulations. More particularly, the indicators with the poorest results were the absence of links to the specific regulations, calendars of events that had not been updated, absence of a directory of those in charge of projects, inexistence of links to software needed to view documents, lack of information about EHEA programmes, no follow-up to monitor the status of announcements and the absence of a news section.

From our findings we can conclude that the subcriteria that allow distinctions to be made between the different universities as regards diffusion of the EHEA are the following: general information, congresses, programmes, announcements, the way latest information is highlighted and a directory of those responsible for projects.

\section{Quality assessment}

In order to determine how much importance is granted by those responsible for these resources to assessment of the quality of their website, 3 indicators were proposed: the existence of a document stating the policy concerning the quality of the web, the existence of a suggestion box that allows users to help to improve the resource, and the existence of surveys on users' satisfaction.

Our results are not particularly encouraging - the mean score of all the universities was 0.6 out of a total of 3 points. There were 22 universities (48.9\%) that did not score at all in the 3 criteria, only one university (Burgos) defines its quality policy and only 2 universities carried out surveys to find out how satisfied users were with the resource; half the universities did not even have a suggestion box. 


\begin{tabular}{|l|c|c|l|}
\hline RATING & FREQUENCY & PERCENTAGE & UNIVERSITIES \\
\hline VG & 1 & 2.22 & Ubu \\
\hline G & 1 & 2.22 & Uah \\
\hline P & 21 & 46.67 & $\begin{array}{l}\text { Uva, upc, uv, uniovi, ugr, uji, udc, umh, uam, upct, } \\
\text { uclm, ucm, uvigo, um, uhu, uib, unavarra, uned, } \\
\text { unican, uma, uc3m }\end{array}$ \\
\hline NA & 22 & 48.89 & $\begin{array}{l}\text { Ua, ub, ual, unex, ehu, us, uab, upo, urv, usc, uca, } \\
\text { upv, upm, upf, ull, urjc, unileon, ujaen, unizar, udl, } \\
\text { usal, ulpgc }\end{array}$ \\
\hline
\end{tabular}

\section{Navigability}

The mean score on this criterion was 3.9 out of 6 points, and striking differences were observed between universities: 30 universities (66.7\%) were rated as Very good, 4 (8.9\%) were Regular and $11(24.4 \%)$ were Not acceptable.

\begin{tabular}{|c|c|c|c|}
\hline RATING & FREQUENCY & PERCENTAGE & UNIVERSITIES \\
\hline $\mathrm{VG}$ & 30 & $66.7 \%$ & $\begin{array}{l}\text { Uv, unex, us, udc, urv, uah, unavarra, urjc, ua, uva, } \\
\text { upc, ub, uniovi, ual, ugr, uji, ehu, umh, uab, uam, } \\
\text { ubu, usc, ucm, upv, uvigo, uhu, uib, uned, unican, } \\
\text { unizar }\end{array}$ \\
\hline $\mathrm{P}$ & 4 & $8.89 \%$ & Upo, uclm, upm, um \\
\hline NA & 11 & $24.4 \%$ & $\begin{array}{l}\text { Uca, upct, upf, ull, uma, ujaen, uc3m, usal, unileon, } \\
\text { udl, ulpgc }\end{array}$ \\
\hline
\end{tabular}

We also looked at whether the contents menu was always visible and in the same place, since it is one of the most useful tools for navigating inside hypertext resources. Results showed that $66.7 \%$ of the universities satisfied this indicator, which can be considered to be a positive result. Consistent use of terminology (that is to say, it is concise and always the same) was observed in 42 out of the 45 universities (93.3\%); in contrast, very few universities provided their websites with navigation buttons $(26.7 \%)$. 


\section{Overall rating}

If we turn to look at the overall results of the universities, which are shown in the following table ${ }^{*}$, it can be seen that there are no extreme values, no university is rated as Very good or Not acceptable; all the universities are rated as being Regular ( 8 universities, 17.8\%), Acceptable (30 universities, 66.7\%) or Good (7 universities, 15.6\%), the mean score being 50 out of 100 points. It can also been seen that the universities "pass" in Authority, Diffusion and Navigability, while they "fail" in Visibility, Currency, Accessibility and Quality.

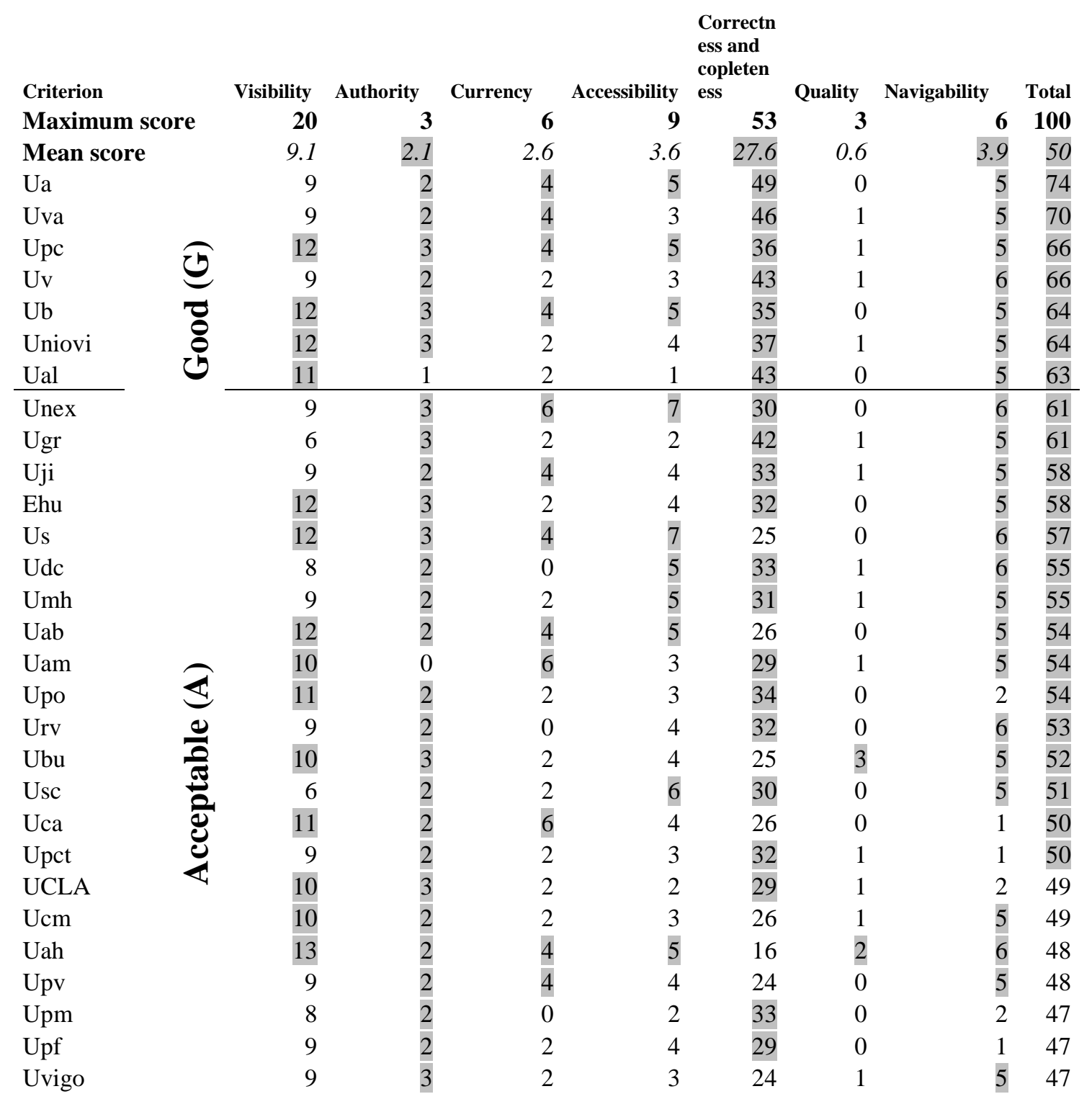

\footnotetext{
* Positive scores both for each criterion and overall are shown highlighted in the table
} 


\begin{tabular}{|c|c|c|c|c|c|c|c|c|c|}
\hline Ull & & 9 & 2 & 2 & 2 & 30 & 0 & 1 & 46 \\
\hline Um & & 9 & 1 & 2 & 5 & 18 & 1 & 2 & 46 \\
\hline Uhu & & 6 & 2 & 2 & 2 & 27 & 1 & 5 & 45 \\
\hline Uib & & 5 & 3 & 4 & 4 & 23 & 1 & 5 & 45 \\
\hline Unavarra & & 3 & 2 & 0 & 5 & 28 & 1 & 6 & 45 \\
\hline Urjc & & 10 & 2 & 2 & 6 & 17 & 0 & 6 & 43 \\
\hline Uned & & 11 & 2 & 2 & 2 & 18 & 1 & 5 & 41 \\
\hline Unican & & 6 & 2 & 2 & 2 & 19 & 1 & 5 & 37 \\
\hline Unileon & & 10 & 2 & 2 & 2 & 21 & 0 & 0 & 37 \\
\hline Uma & & 10 & 2 & 2 & 2 & 19 & 1 & 1 & 37 \\
\hline Ujaen & & 6 & 3 & 4 & 3 & 18 & 0 & 1 & 35 \\
\hline Unizar & & 9 & 2 & 2 & 4 & 13 & 0 & 5 & 35 \\
\hline Uc3m & E & 9 & 0 & 2 & 2 & 19 & 1 & 1 & 34 \\
\hline Udl & 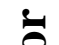 & 10 & 2 & 2 & 3 & 14 & 0 & 0 & 31 \\
\hline Usal & 0 & 8 & 0 & 4 & 2 & 11 & 0 & 1 & 26 \\
\hline Ulpgc & an & 3 & 2 & 0 & 3 & 17 & 0 & 0 & 25 \\
\hline
\end{tabular}

Since the main purpose of this study was to determine the visibility and diffusion of the EHEA, the following graph was plotted to show the position of the universities according to their coordinates in terms of Visibility and Diffusion. The $\mathrm{X}$ and $\mathrm{Y}$ axes take a value of " 0 " at the mean of each of these criteria and the coordinates are obtained by subtracting the value of each university from the mean. Thus, the top right quadrant contains the universities that obtained the best scores in both criteria, and those with the poorest scores are situated in the bottom left quadrant; those with good visibility and poor diffusion are at bottom right and the top left quadrant contains those with good diffusion and poor visibility. There is a certain balance among the four quadrants, the one reflecting the poorest practices being the one with the fewest universities in it. 


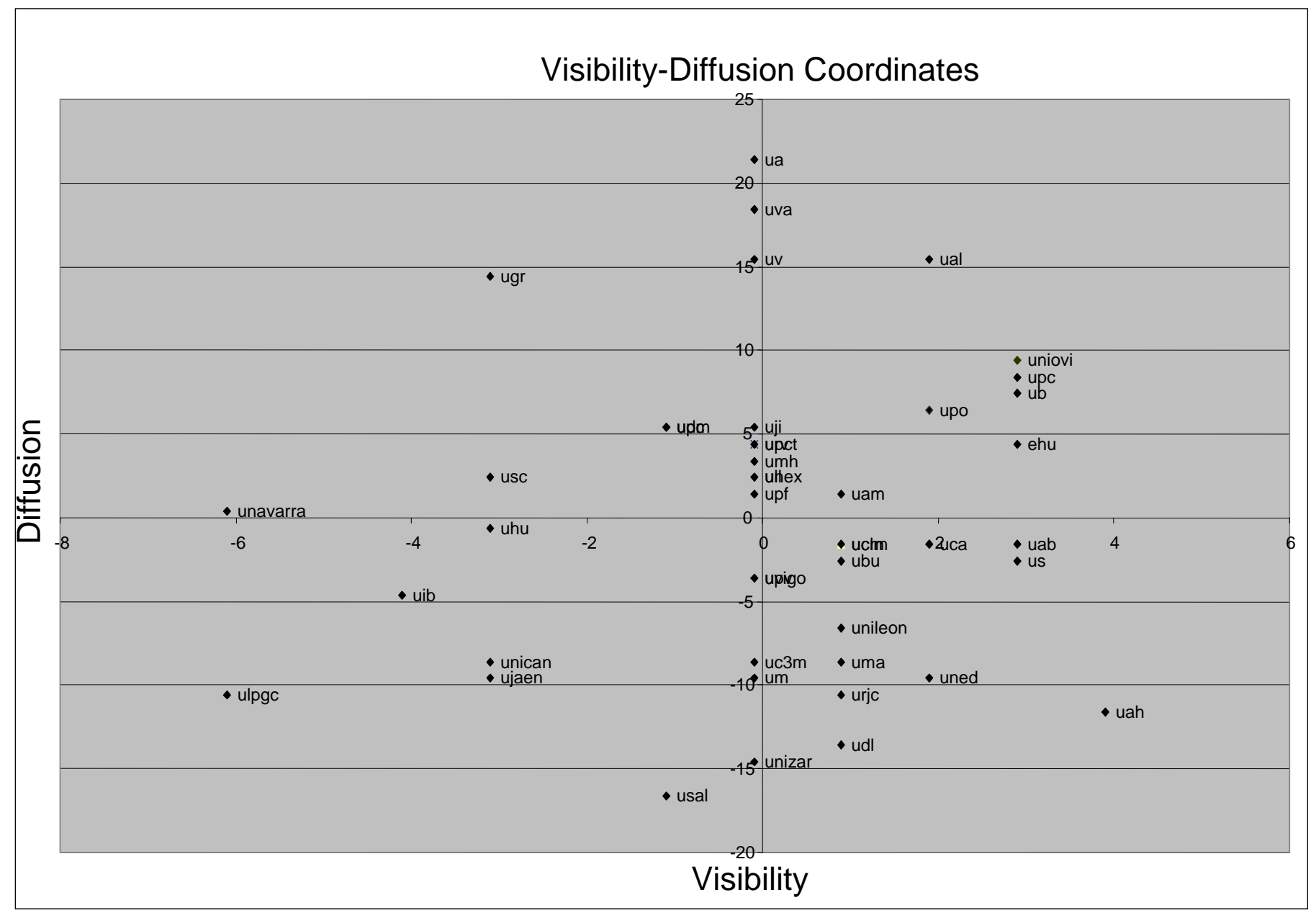

6. Conclusions

The Spanish public universities are aware of the interest that information about the EHEA holds for the university community, and they also understand the need to have a website to disseminate such information, as is shown by the fact that 45 of the 48 universities considered in the study dedicated space on their website to the subject. They must, however, improve the way they disseminate the information in order to make it more useful. They have to offer good contents (rigorous, clear and up-to-date) and they must ensure these are easy to find, access and consult.

In the light of the results obtained, which should be appraised taking into account the limitations of the study (that is to say, the fact that data were collected using a particular set of indicators that are by no means the only ones possible), it could be deduced that the situation is not 
altogether bad but neither is it too good; the overall rating is Acceptable and the mean score is $50 \%$ of the maximum possible score. Without a doubt improvements are needed.

This study enabled us to analyse the situation of Spanish public universities as far as this issue is concerned, and at the same allowed us to determine their main weaknesses, that is, the aspects most in need of improvement. In this way we were able to detect the overall shortcomings that exist in the universities, the most serious being those referring to quality assessment (especially the definition of quality policies and surveys of users) and accessibility (WAI regulations); they are less pronounced in matters concerning visibility and updating the resource. The variations in the results obtained by the different universities' EHEA websites do not seem to be related to the universities' characteristics (new or old, geographical location, etc), since any Spanish university can acquire the human and financial resources required for creating and maintaining a portal: the cause is more likely to lie in the universities' degree of awareness of the importance of offering quality web resources in a world where the Internet rules, and in the importance they attach to the European higher education convergence process.

One important benefit deriving from this research is that it allows each university to know its weak points as regards the way it disseminates information about the EHEA on their websites. It would therefore be possible to conduct a SWOT analysis on each university from the findings of this study, as a first step towards improvement. In addition, this work somehow makes the improvement process easier for them by identifying the best practices in each of the aspects that were analysed. It is worth making the effort because European convergence as far as higher education is concerned requires universities to measure up to this new dynamic context where the culture of quality is a driving force.

\section{References}

ALEXANDER, J.; TATE, M.A. (1999), Web Wisdom: How to evaluate and create information quality on the web, Lawrence Erlbaum Associates, New Jersey.

BARNES, S.J. AND R.T. VIDGEN (2001), An Evaluation of Cyber-Bookshops: The WebQual Method, International Journal of Electronic Commerce, 6 : 6-25. 
BARNES, S., VIDGEN, R. (2002), An integrative approach to the assessment of e-commerce quality, Journal of Electronic Research, 3 (3) : 114-127.

BECK, S. (1997), "Evaluation Criteria." The Good, The Bad \& The Ugly: or, Why It's a Good Idea to Evaluate Web Sources. [On-line]. Available: http://lib.nmsu.edu/instruction/evalcrit.html

BERNSTAM, E. V.; SHELTON, D. M.; WALJI, M.; MERIC-BERNSTAM, F. (2005), Instruments to assess the quality of health information on the World Wide Web: what can our patients actually use? International Journal of Medical Informatics, 74: 13-19.

CHAO, H. (2002), Assessing the quality of academia libraries on the Web: the development and testing of criteria, Library \& Information Science Research, 24: 169-194.

CLAUSEN, H. (1999), Evaluation of library web sites: the Danish case. The electronic library, $17(2): 83-87$.

CORRY, M. D., FRICK, T. W., HANSEN, L. (1997), User-centered design and usability testing of a Web site: An illustrative case study, Educational Technology Research and Development, 45 (4): 65-76.

EUROPEAN COMMISSION (2001a), Hacer realidad un espacio europeo del aprendizaje permanente [On-line]. Available: http://europa.eu.int/comm/education/policies/ll1/life/communication/com_es.pdf

EUROPEAN COMMISSION (2001b), Plan de Acción eLearning: Concebir la Educación del Futuro. [On-line]. Available:

http://europa.eu.int/eur-lex/es/com/cnc/2001/com2001 0172es01.pdf

GONZÁLEZ, J. \& WAGENAAR, R. (eds.) (2003), Tuning educational structures in Europe: final report: phase one. Universidad de Deusto, Bilbao, Universidad de Groningen, Groningen. [On-line]. Available: http://www.relint.deusto.es/TuningProject/index.htm GORSKI, P. (1999), Toward a multicultural approach for evaluating educational web sites. [Online]. Available: http://edchange.org/multicultural/net/comps/eval.html 
HADDOW, G. (2003), Focusing on health information: how to assess information quality on the internet, Australian Library Journal, 52 (2). [on line]. Available: http://alia.org.au/publishing/alj/52.2/full.text/haddow.html

HOLMES, M. (2002), Web Usability and Navigation: A Beginner.s Guide, Osborne/McGrawHill, Berkeley, London.

JADAD, A.R., GAGLIARDI, A. (1998), Rating health information on the Internet: navigating to knowledge or to Babel? JAMA 279 (8) : 611-614.

KAPOUN, J. (1998), Teaching undergrads WEB evaluation: A guide for library instruction, C\&RL News, 59 (1). [On-line]. Available:

http://www.ala.org/ala/acrl/acrlpubs/crlnews/backissues1998/julyaugust6/teachingunder grads.htm.

KIM P., ENG T.R., DEERING M.J., MAXFIELD A. (1999), Published criteria for evaluating health related web sites: review, BMJ 318 (7184) : 647-649.

MARQUÉS GRAELS, P. (2000), Criterios de calidad para los espacios web educativos. [On line]. Available: http://dewey.uab.es/pmarques/caliweb.htm

MILLER, H. (1996), The multiple dimensions of information quality, Information systems management, $13(2): 79-83$.

MIRANDA GONZÁLEZ, F.J.; BAŃEGIL PALACIOS, T.M. (2004), Quantitative evaluation of commercial web sites: an empirical study of Spanish firms. International Journal of Information Management, 24 : 313-328.

OLSINA, L., GODOY, D., LAFUENTE, G., ROSSI, G. (1999), Quality characteristics and attributes for academic Web sites, Web Engineering Workshop at WWW8, Toronto, Canada.

OVERBEEKE, M., SNIZEK, W. (2005), Web sites and coorporate culture: a research note. Business \& Society, 44 (3): 346-356.

PINTO, M., coord. (2003), Visibilidad de la investigación de las universidades españolas a través de sus páginas web en el ámbito del Espacio Europeo de Enseñanza Superior: 
análisis, evaluación y mejora de la calidad. Proyecto EA2003-0012. Ministerio de Educación y Ciencia, Madrid.

PINTO, M., ALONSO, J.L., CORDÓN, J.A., FERNANDEZ, V., GARCIA, C., GARCIA, J., GOMEZ, C., ZAZO, A.F. (2005), Quality assessment of Spanish universities's web sites focused on the European Research Area. Scientometrics, 65 (1): 67-93.

REICHERT, S. \& TAUCH, C. (2005), Trends in European Higher Education. European Universities Implementing Bologna. European University Association (EUA). [On-line]. Available: http://www.eua.be/eua/jsp/en/upload/TrendsIV_FINAL.1117012084971.pdf SPOOL, J. M. (1999), Web Site Usability: A Designer's Guide, Morgan Kaufmann Publishers, San Francisco.

SELLITTO C., BURGESS, S. (2005), Towards a weighted average framework for evaluating the quality of web-located health information, Journal of Information Science,. 31: 260272.

SMITH, A. G. (1997), Testing the Surf: Criteria for Evaluating Internet Information Resources, The Public-Access Computer Systems Review, 8 (3). [On-line]. Available: http://info.lib.uh.edu/pr/v8/n3/smit8n3.html

WANG, P, HAWK, W.B., TENOPIR, C. (2000), Users' interaction with World Wide Web resources: an exploratory study using a holistic approach, Information processing and management, 36: 229-251.

W3C. (1997), The World-Wide Web Virtual Library. [On-line]. Available: http://www.w3.org/vl

W3C. (1999), Checklist of Checkpoints for Web Content Accessibility Guidelines 1.0. [On-line]. Available: http://www.w3.org/TR/WCAG10/full-checklist.html.

ZHANG, J.; DIMITROFF, A. (2000), The impact of metadata implementation on webpage visibility in search engine results (Part II), Information processing and management, 41: $691-715$ 